\title{
Critical care of subarachnoid haemorrhage
}

\author{
Michael J. Souter
}

\begin{abstract}
Subarachnoid haemorrhage (SAH) is a consistent presentation of haemorrhagic stroke of significance to clinicians in neurocritical care, inducing consequent effects on non-neurological systems, while at the same time, rendering the brain vulnerable to secondary physiological insult modifying neurological outcome, despite control of the original point of haemorrhage. Coordinated treatment depends on comprehensive evaluation of both cerebral and systemic physiology, identifying and treating impaired function. The presence of a dedicated neurocritical care team can benefit outcome. Protocols of care have evolved to meet evidence-based challenges, discarding potentially deleterious components of hypervolaemia and haemodilution, while maintaining pressure-guided perfusion. Treatment targets have also evolved with a shift in focus away from SAH-associated vasospasm, towards actual ischaemic outcome - illustrated by lack of effectiveness of pharmaceutical treatments of vasospasm. Clinicians must consequently review pathophysiological mechanisms of injury and devise new treatment opportunities.
\end{abstract}

Key words: Brain, critical care, secondary insult, subarachnoid haemorrhage

\section{INTRODUCTION}

Aneurysmal subarachnoid haemorrhage (aSAH) is a subtype of haemorrhagic stroke of sustained relevance to neuroanaesthesia and neurocritical care across countries and continents, accounting for $3 \%$ of all strokes. ${ }^{[1]}$ The incidence of SAH ranges from 2 to 22 patients per 100,000 population per year, with greatest numbers in Finland and Japan. ${ }^{[2-4]}$ Mortality ranges from $26 \%$ to $50 \%$, with a $21 \%$ risk of death in first $24 \mathrm{~h}$ after haemorrhage, increasing to $37 \%$ and $44 \%$ at 7 and 30 days, respectively. ${ }^{[5]}$ The pre-hospital mortality of $12 \%-15 \%$ cannot be ignored and may contribute to greater hospital mortality as detection, primary support and referral mechanisms evolve. ${ }^{[2]}$

Department of Anesthesiology and Pain Medicine, University of Washington School of Medicine, Harborview Medical Center, Seattle, WA, USA

Address for correspondence:

Prof. Michael J. Souter, Department of Anesthesiology and Pain Medicine, University of Washington School of Medicine, Harborview Medical Center, 325 Ninth Avenue, Seattle, WA, USA.

E-mail: msouter@uw.edu

\begin{tabular}{|l|l|}
\hline \multicolumn{2}{|c|}{ Access this article online } \\
\hline Quick Response Code: & Website: \\
\hline & www.jnaccjournal.org \\
\cline { 2 - 2 } & \\
\hline
\end{tabular}

Risk factors for aneurysmal haemorrhage include a family history of aSAH (especially in a first-degree relative), hypertension, tobacco smoking, use of cocaine (and other sympathomimetics), having a known aneurysm $>7 \mathrm{~mm}$ in size and presence of an aneurysm in the posterior communicating artery or in the posterior circulation. ${ }^{[2]}$

\section{PATHOPHYSIOLOGY}

There is a $1 \%-6 \%$ incidence of previously unidentified aneurysms detected at autopsy and some familial clustering of aSAH. There are also identified connective tissue disorders well associated with higher risk, for example, Ehlers-Danlos syndrome, neurofibromatosis type I, Marfan syndrome and autosomal dominant polycystic kidney disease. ${ }^{[6]}$ This led to some belief that aneurysms arise due to congenital defects in the arterial wall structure. Fine anatomic studies and improved insights into the degenerative consequences of atherosclerotic disease, flow dynamics and wall shear stress on the muscular layers of the artery have largely disproved this assumption, validated by the presence of

This is an open access article distributed under the terms of the Creative Commons Attribution-NonCommercial-ShareAlike 3.0 License, which allows others to remix, tweak, and build upon the work non-commercially, as long as the author is credited and the new creations are licensed under the identical terms.

For reprints contact: reprints@medknow.com

How to cite this article: Souter MJ. Critical care of subarachnoid haemorrhage. J Neuroanaesthesiol Crit Care 2017;4:S49-55. 
aneurysms around points of branch turbulence and/or highly pulsatile oscillations of flow. ${ }^{[7]}$

Those interactions of flow and a pathologically weakened arterial musculature facilitate the formation and expansion of aneurysms to the point that they exceed vessel wall strength, with consequent rupture and haemorrhage into parenchyma or the subarachnoid space. Other causes of SAH are listed in Table 1.

\section{CLINICAL FEATURES}

Typically, patients with aSAH present with sudden onset of a severe headache, often described as the 'worst headache of life.' However, it should be noted that only $6 \%-17 \%$ of patients presenting with a sudden severe headache will, in fact, turn out to have aSAH. ${ }^{[8,9]}$ Other typical symptoms include seizure, loss of consciousness and sudden vomiting along with onset of headache [Table 2]..$^{[8]}$

Up to $50 \%$ of patients describe a 'sentinel headache' or 'herald bleed' a similar sudden onset severe headache

\section{Table 1: Other causes of subarachnoid haem- orrhage}

\begin{tabular}{l}
\hline Head trauma \\
Perimesencephalic haemorrhage \\
Arteriovenous malformation rupture \\
Dural arteriovenous fistula \\
Mycotic aneurysm \\
Cocaine, methamphetamine or other sympathomimetic \\
abuse \\
Hypertensive crisis \\
Moyamoya syndrome \\
Central nervous system vasculitis \\
Call-Fleming syndrome(reversiblecerebral vasoconstriction \\
syndrome) \\
Intradural vertebral artery dissection \\
Pituitary apoplexy
\end{tabular}

\section{Table 2: Common presenting features}

Sentinel leaks - 30\%-50\%
Meningitis - $80 \%$
Loss of consciousness - $45 \%$ at ictus, $10 \%$ for several days
Seizures - 10\%-25\%
Focal neurology - 25\% (hemiparesis, aphasia, hemineglect,
cranial nerve palsies and memory loss)
Motor deficits - $10 \%-15 \%$
Retinal haemorrhage (Terson's syndrome) - $20 \%-30 \%$
Hypertension - $50 \%$

that presents around 3-7 days prior, but spontaneously resolves. This is thought due to small tears or 'micro-leaks' from aneurysm, which eventually rupture to cause the main haemorrhage.

Physical findings are often non-specific but may include depressed level of consciousness or confusion. A new third cranial nerve palsy may be associated with an ipsilateral posterior communicating artery aneurysm compressing or stretching the adjacent nerve.

\section{DIAGNOSIS}

Following the clinical presentation, diagnosis is usually confirmed by non-contrast head computed tomography (CT), which is highly sensitive to acute bleeding, but that sensitivity attenuates with time. ${ }^{[10]}$

If that initial head CT does not reveal SAH, a lumbar puncture should be performed. Xanthochromia will appear $6 \mathrm{~h}$ after haemorrhage or other cause of presentation and is best detected by spectrophotometry. ${ }^{[1]}$

Magnetic resonance imaging may also be employed where the initial head CT was negative, but there is a strong clinical history of $>72 \mathrm{~h}$ duration. ${ }^{[12]}$

The gold standard remains digital angiography although CT angiography (CTA) has become increasingly helpful and can often be used more easily and quickly than catheter studies. Three-dimensional CTA allows simulated perspective and planning of the surgical approach although vessels $<1 \mathrm{~mm}$ are not usually seen. ${ }^{[13]}$

The conventional cerebral angiogram, however, still provides the best definition of aneurysmal and vascular anatomy to facilitate surgical planning. If a first angiogram is negative, there is a $6 \%$ detection rate of an aneurysm on repeat angiography around 1 week later. ${ }^{[14]}$

\section{GRADING SCALES}

Grading of the severity of aneurysmal haemorrhage allows comparison of severity, efficacy of care and outcomes. The Hunt and Hess $(\mathrm{H}$ and $\mathrm{H}) \mathrm{scale}^{[15]}$ and World Federation of Neurological Surgeons (WFNS) scale ${ }^{[16]}$ are common clinical scales in use, while the Fisher grading scale is a radiologic scale that was used to predict the risk of vasospasm. ${ }^{[1]]}$ The $\mathrm{H}$ and $\mathrm{H}$ scale has been criticised for high degrees of inter-observer variability and relatively coarse discrimination of outcome. ${ }^{[16]}$ The WFNS scale combines the Glasgow coma scale score with the presence or absence of focal deficits, with a more graduated relationship to outcome. The Prognosis on Admission of Aneurysmal Subarachnoid Haemorrhage scale is a relatively new score with possibly better prognostic discrimination. ${ }^{[18]}$ The Fisher scale has been 
criticised for confusing outcome with progression through the stages of severity, where a grade III may have a worse outcome than a grade IV.

\section{TREATMENT}

Treatment goals in aSAH are prioritised on, first, prevention of re-bleeding, followed by aneurysmal obliteration, with subsequent monitoring for delayed cerebral ischaemia (DCI).

There is a $4 \%-17 \%$ re-bleeding rate with aSAH in the first $72 \mathrm{~h}$ after presentation, with a mortality between $50 \%$ and $60 \%{ }^{[19-21]}$ Anti-fibrinolytics were used historically but increased the risk of $\mathrm{DCI}^{[22]}$ and hydrocephalus. ${ }^{[23]}$ There is renewed interest in brief courses of $<72 \mathrm{~h}$ where treatment of aneurysm is delayed by patient instability, but there are still concerns of hydrocephalus. ${ }^{[24]}$

Control of blood pressure has also been thought to reduce re-bleeding rates but with very little concrete evidence to support definitive blood pressure targets. ${ }^{[25]}$ Suggested systolic targets range between 90 and $140 \mathrm{mmHg}$, while there is concern for increased risk of ischaemic stroke with aggressive reductions. ${ }^{[26]}$

Early treatment of aneurysm logically reduces concerns for blood pressure management and is performed by surgical clipping or endovascular coiling of aneurysm. Choice of treatment differs widely across the world with increasing endovascular use in Europe, but less so in the United States. Many factors may influence that decision including patient's age, aneurysm location, shape and size, presence of haematoma, along with patient's comorbidities and clinical state.

\section{HYDROCEPHALUS}

Acute hydrocephalus occurs in up to $20 \%$ of patients with $\mathrm{aSAH},{ }^{[27]}$ with age, female gender, poor $\mathrm{H}$ and $\mathrm{H}$ grade on admission posterior location and Fisher grade 4, associated with increased risk. ${ }^{[28]}$ Persistent headache, loss of upward gaze and cognitive impairment are typical, with that latter aspect often being confused with vasospasm. Those symptoms can be improved by drainage, ${ }^{[29]}$ and any severely obtunded patient should be considered for a trial of external cerebrospinal fluid drainage before definitive prognostication or limitation of care.

\section{DELAYED CEREBRAL ISCHAEMIA}

DCI is the main cause of morbidity after aSAH, arising in up to one-third of patients presenting with aSAH. ${ }^{[30]}$ Reversible constriction of the cerebral vasculature - vasospasm - occurs in two-thirds of patients presenting with aSAH. ${ }^{[31]}$ While it is a recognised cause of DCI, recent effective treatments of vasospasm have not improved neurological outcomes. ${ }^{[32]}$ The consequent interpretation is that ischaemia arises from other causes such as spreading cortical depolarisation or cerebral microcirculatory thrombosis, for which vasospasm may be just an epiphenomenon. ${ }^{[32,33]}$

This does not mean that vasospasm should be ignored, but rather that its treatment should be focused on and titrated towards measures of functional neurologic outcome, rather than the surrogate features of vasospasm. ${ }^{[34]}$

Cerebral vasospasm occurs between days 3 and 14, following aSAH with a peak incidence at 7-10 days, with highest risks seen in those with large amounts of blood in the subarachnoid and intraventricular spaces. ${ }^{[35]}$ Clinical presentation includes decreased level of consciousness, confusion and new focal neurologic deficit.

Consequently, clinical examination still offers the best combination of sensitivity and specificity to neurological deterioration.

Transcranial Doppler monitoring uses ultrasound assessment of cerebral arterial flow velocity to assess cerebral perfusion, with increasing confidence of vasospasm as velocity rises. The Lindegaard ratio is a comparison of velocities between the extracranial internal cerebral artery and ipsilateral middle cerebral artery. Ratios above six indicate severe spasm, while moderate vasospasm is associated with ratios over $3 .{ }^{[36]}$

Other modalities such as cerebral microdialysis and continuous electroencephalogram are employed but remain unproven modifiers of outcome.

With a premise that cerebral vasospasm reduces perfusion to the extent that it induces ischaemic change, treatment is based on the restoration of adequate levels of blood flow to meet demand. 'Triple-H therapy' (induced hypertension, induced hypervolaemia and haemodilution) has been practiced for over 40 years, but with emerging concern of complications and questionable efficacy. ${ }^{[37-39]}$ Increasing practice has been refined to concentrate on induced hypertension in circumstances of euvolaemia. While this has been demonstrated to improve individual outcomes, effective pharmacological treatment of vasospasm has not improved neurologic outcomes, suggesting other additional mechanisms of injury. ${ }^{[32,40]}$

Nimodipine has a modest reduction of the risk of poor outcome after aSAH but does not affect vasospasm. ${ }^{[41,42]}$ It may have fibrinolytic effects, reducing microcirculatory thrombosis, which is a postulated mechanism of cerebral ischaemia. ${ }^{[43]}$ However, endovascular rescue therapy 
may be employed to treat cerebral vasospasm, delivering intra-arterial vasodilators by selective catheterisation, which may, in turn, allow balloon angioplasty of those vasospastic segments. ${ }^{[4-47]}$

\section{SECONDARY INSULTS}

Neurological outcome is considerably modified by secondary insults involving other than the central nervous system, many of which offer potential for treatment or modification within the ICU. ${ }^{[48]}$

The 'brain-heart axis' is now well appreciated with acute neurologic disease processes manifesting changes upon cardiac function. These range from frequently observed changes in electrocardiogram (ECG) morphology and rhythm, ${ }^{[49]}$ through abnormal perfusion scans for over $30 \%$ of SAH patients, ${ }^{[50]}$ troponinemia in a similar proportion, ${ }^{[51]}$ to abnormal echocardiography $(8 \%-10 \%$ of SAH patients), most marked in those with basal cistern haemorrhage. ${ }^{[52]}$ ECG changes have little effect on outcome, whereas troponinemia is associated with a higher incidence of reduction in ejection fraction and the presence of regional wall abnormalities.

This entity of neurologic 'myocardial stunning' is functionally related to takotsubo cardiomyopathy, ${ }^{[53]}$ and similar to that entity, there is no indication for acute treatment of coronary ischaemia. Function recovers well within a matter of days. Both SAH and coronary artery disease share many risk factors including age, and the possibility of coincident acute coronary occlusion should not be totally dismissed.

The SAH patient typically presents with the worst headache of life - the pain and agitation of which usually indicate some intervention to limit blood pressure. The presence of pain and no requirement for blood pressure control should raise some suspicions of neurologic stunning - especially when accompanied by QTc prolongation, symmetrical $\mathrm{T}$ inversion and troponin elevation. Early echocardiography is indicated as this may determine whether surgical clipping or endovascular treatment is appropriate. ${ }^{[52]}$

Even after aneurysmal occlusion, myocardial stunning may induce a choice to proceed to early angioplasty as opposed to pressure elevation. ${ }^{[54]}$

Lung injury of some form is a frequent accompaniment in over $40 \%$ of patients with SAH, with around $12 \%$ experiencing severe effects. ${ }^{[55]}$ Myocardial dysfunction may be associated, but there is potential induction of systemic inflammatory response with cerebral release of cytokines into the cardiopulmonary circulation..$^{[56]}$ This risk of lung injury is increased by transfusion. ${ }^{[57]}$
It is important to note that while worse neurological outcomes are seen in anaemic patients, transfusion is not associated with better outcomes but may rather worsen the risks. ${ }^{[58]}$ Given that, many of the cardinal studies in ICU transfusion excluded neurological patients. There is no good body of evidence to drive practice - many (including my own unit) effect compromise with a transfusion haematocrit trigger of 25 as opposed to 21 , employed in general ICU practice.

A significantly more prevalent risk factor is fever, with a discernible effect on outcome. ${ }^{[48,59,60]}$ Fever correction to normothermia is the mainstay of treatment. Hypothermia has not shown benefit and complicates care. ${ }^{[6]]}$

Fluid and electrolyte abnormalities are common in patients with SAH, with around $40 \%$ of patients experiencing hyponatraemia. ${ }^{[62]}$ Argument continues as to whether the cause is cerebral salt wasting syndrome (CSWS) ${ }^{[63,64]}$ or the syndrome of inappropriate antidiuretic hormone. ${ }^{[65]}$ This author has seen patients who demonstrate convincing evidence of both - but this is rare. Treatment differs according to cause with implications to volume status. The observed frequency of polyuria supports a higher incidence of CSWS, but this may be complicated by a natriuretic response to pressure elevation and volume loading. ${ }^{[66]}$

Enterally administered salt tablets are often enough to limit derangements - especially when combined with free water restriction. If there is a large urinary sodium loss, then fludrocortisone is indicated. Plasma and urine analysis will help decision-making. Hypertonic saline infusions may be indicated in circumstances of significant hyponatraemia below $130 \mathrm{mEq} / \mathrm{L}$.

Many of these patients are anorexic, consequent to pain, nausea and opiate analgesia. There is a consequent risk of negative catabolism in the context of the significantly elevated energy requirements associated with $\mathrm{SAH}^{[67]}$ - which in turn induces a negative nitrogen balance. That negative balance is associated with both hypoalbuminaemia - further reducing intravascular volume $^{[68]}$ - and increased risks of hospital-acquired infection and adverse outcome. ${ }^{[69]}$

\section{SUMMARY}

$\mathrm{SAH}$ is an acute threat to life which, even after being treated, presents subsequent features of neurologic, cardiac, pulmonary, endocrine and nutritional dysfunction. This indicates a need for a comprehensive holistic appraisal of pathophysiology, which adds value to a dedicated neurocritical care team, a concept that has been validated by reductions of in-hospital mortality and length of stay. ${ }^{[70-72]}$ 
Financial support and sponsorship Nil.

\section{Conflicts of interest}

There are no conflicts of interest.

\section{REFERENCES}

1. Johnston SC, Selvin S, Gress DR. The burden, trends, and demographics of mortality from subarachnoid hemorrhage. Neurology 1998;50:1413-8.

2. Connolly ES Jr., Rabinstein AA, Carhuapoma JR, Derdeyn CP, Dion J, Higashida RT, et al. Guidelines for the management of aneurysmal subarachnoid hemorrhage: A guideline for healthcare professionals from the American Heart Association/ American Stroke Association. Stroke 2012;43:1711-37.

3. Feigin VL, Lawes CM, Bennett DA, Barker-Collo SL, Parag V. Worldwide stroke incidence and early case fatality reported in 56 population-based studies: A systematic review. Lancet Neurol 2009;8:355-69.

4. Ingall $\mathrm{T}$, Asplund $\mathrm{K}$, Mähönen $\mathrm{M}$, Bonita R. A multinational comparison of subarachnoid hemorrhage epidemiology in the WHO MONICA stroke study. Stroke 2000;31:1054-61.

5. Pobereskin LH. Incidence and outcome of subarachnoid haemorrhage: A retrospective population based study. J Neurol Neurosurg Psychiatry 2001;70:340-3.

6. Schievink WI. Intracranial aneurysms. N Engl J Med 1997;336:28-40.

7. Sforza DM, Putman CM, Cebral JR. Hemodynamics of cerebral aneurysms. Annu Rev Fluid Mech 2009;41:91-107.

8. Linn FH, Wijdicks EF, van der GraafY, Weerdesteyn-van Vliet FA, Bartelds AI, van Gijn J. Prospective study of sentinel headache in aneurysmal subarachnoid haemorrhage. Lancet 1994;344:590-3.

9. Morgenstern LB, Luna-Gonzales H, Huber JC Jr., Wong SS, Uthman MO, Gurian $\mathrm{JH}$, et al. Worst headache and subarachnoid hemorrhage: Prospective, modern computed tomography and spinal fluid analysis. Ann Emerg Med 1998;32(3 Pt 1):297-304.

10. Edlow JA, Caplan LR. Avoiding pitfalls in the diagnosis of subarachnoid hemorrhage. N Engl J Med 2000;342:29-36.

11. Perry JJ, Sivilotti ML, Stiell IG, Wells GA, Raymond J, Mortensen M, et al. Should spectrophotometry be used to identify xanthochromia in the cerebrospinal fluid of alert patients suspected of having subarachnoid hemorrhage? Stroke 2006;37:2467-72.

12. U-King-Im JM, Koo B, Trivedi RA, Higgins NJ, Tay KY, Cross JJ, et al. Current diagnostic approaches to subarachnoid haemorrhage. Eur Radiol 2005;15:1135-47.

13. Kumar A, Kato Y, Hayakawa M, Junpei O, Watabe $T$, Imizu S, et al. Recent advances in diagnostic approaches for sub-arachnoid hemorrhage. Asian J Neurosurg 2011;6:94-8.

14. Urbach H, Zentner J, Solymosi L. The need for repeat angiography in subarachnoid haemorrhage. Neuroradiology 1998;40:6-10.

15. Hunt WE, Hess RM. Surgical risk as related to time of intervention in the repair of intracranial aneurysms. J Neurosurg 1968;28:14-20.

16. Report of World Federation of Neurological Surgeons Committee on a universal subarachnoid hemorrhage grading scale. J Neurosurg 1988;68:985-6.

17. Fisher CM, Kistler JP, Davis JM. Relation of cerebral vasospasm to subarachnoid hemorrhage visualized by computerized tomographic scanning. Neurosurgery 1980;6:1-9.

18. van Heuven AW, Dorhout Mees SM, Algra A, Rinkel GJ. Validation of a prognostic subarachnoid hemorrhage grading scale derived directly from the Glasgow Coma Scale. Stroke 2008;39:1347-8.

19. Starke RM, Connolly ES Jr., Participants in the international multi-disciplinary consensus conference on the critical care management of subarachnoid haemorrhage. Rebleeding after aneurysmal subarachnoid hemorrhage. Neurocrit Care 2011;15:241-6.

20. van Gijn J, Rinkel GJ. Subarachnoid haemorrhage: Diagnosis, causes and management. Brain 2001;124(Pt 2):249-78.

21. Larsen CC, Astrup J. Rebleeding after aneurysmal subarachnoid hemorrhage: A literature review. World Neurosurg 2013;79:307-12.

22. Fridriksson $S$, Säveland $H$, Jakobsson $K E$, Edner $G$, Zygmunt S, Brandt L, et al. Intraoperative complications in aneurysm surgery: A prospective national study. J Neurosurg 2002;96:515-22.

23. Pinna G, Pasqualin A, Vivenza C, Da Pian R. Rebleeding, ischaemia and hydrocephalus following anti-fibrinolytic treatment for ruptured cerebral aneurysms: A retrospective clinical study. Acta Neurochir (Wien) 1988;93:77-87.

24. Harrigan MR, Rajneesh KF, Ardelt AA, Fisher WS $3^{\text {rd }}$. Short-term antifibrinolytic therapy before early aneurysm treatment in subarachnoid hemorrhage: Effects on rehemorrhage, cerebral ischemia, and hydrocephalus. Neurosurgery 2010;67:935-9.

25. Suarez JI, Tarr RW, Selman WR. Aneurysmal subarachnoid hemorrhage. N Engl J Med 2006;354:387-96.

26. Wijdicks EF, Vermeulen M, Murray GD, Hijdra A, van Gijn J. The effects of treating hypertension following aneurysmal subarachnoid hemorrhage. Clin Neurol Neurosurg 1990;92:111-7.

27. van Gijn J, Hijdra A, Wijdicks EF, Vermeulen M, van Crevel H. Acute hydrocephalus after aneurysmal subarachnoid hemorrhage. J Neurosurg 1985;63:355-62.

28. Dorai Z, Hynan LS, Kopitnik TA, Samson D. Factors related to hydrocephalus after aneurysmal subarachnoid hemorrhage. Neurosurgery 2003;52:763-9.

29. Ochiai H, Yamakawa Y. Continuous lumbar drainage for the preoperative management of patients with aneurysmal subarachnoid hemorrhage. Neurol Med Chir (Tokyo) 2001;41:576-80.

30. Dorsch NW, King MT. A review of cerebral vasospasm in aneurysmal subarachnoid haemorrhage Part I: Incidence and effects. J Clin Neurosci 1994;1:19-26.

31. Dorsch N. A clinical review of cerebral vasospasm and delayed ischaemia following aneurysm rupture. Acta Neurochir Suppl 2011;110(Pt 1):5-6.

32. Macdonald RL, Higashida RT, Keller E, Mayer SA, Molyneux A, Raabe A, et al. Clazosentan, an endothelin receptor antagonist, in patients with aneurysmal subarachnoid haemorrhage undergoing surgical clipping: A randomised, double-blind, placebo-controlled phase 3 trial (CONSCIOUS-2). Lancet Neurol 2011;10:618-25.

33. Etminan N, Vergouwen MD, Ilodigwe D, Macdonald RL. Effect of pharmaceutical treatment on vasospasm, delayed cerebral ischemia, and clinical outcome in patients with aneurysmal subarachnoid hemorrhage: A systematic review and meta-analysis. J Cereb Blood Flow Metab 2011;31:1443-51.

34. Etminan N, Vergouwen MD, Macdonald RL. Angiographic vasospasm versus cerebral infarction as outcome measures after aneurysmal subarachnoid hemorrhage. Acta Neurochir Suppl 2013;115:33-40.

35. Claassen J, Bernardini GL, Kreiter K, Bates J, Du YE, Copeland D, et al. Effect of cisternal and ventricular blood on risk of delayed cerebral ischemia after subarachnoid hemorrhage: The Fisher scale revisited. Stroke 2001;32:2012-20.

36. Lindegaard KF, Nornes H, Bakke SJ, Sorteberg W, Nakstad P. Cerebral vasospasm diagnosis by means of angiography 
and blood velocity measurements. Acta Neurochir (Wien) 1989;100:12-24.

37. Treggiari MM, Walder B, Suter PM, Romand JA. Systematic review of the prevention of delayed ischemic neurological deficits with hypertension, hypervolemia, and hemodilution therapy following subarachnoid hemorrhage. J Neurosurg 2003;98:978-84.

38. Feigin VL, Rinkel GJ, Algra A, van Gijn J. Circulatory volume expansion for aneurysmal subarachnoid hemorrhage. Cochrane Database Syst Rev 2000;(2):CD000483.

39. Lee KH, Lukovits T, Friedman JA. "Triple-H" therapy for cerebral vasospasm following subarachnoid hemorrhage. Neurocrit Care 2006;4:68-76.

40. Sillberg VA, Wells GA, Perry JJ. Do statins improve outcomes and reduce the incidence of vasospasm after aneurysmal subarachnoid hemorrhage: A meta-analysis. Stroke 2008;39:2622-6.

41. Rinkel GJ, Feigin VL, Algra A, van den Bergh WM, Vermeulen M, van Gijn J. Calcium antagonists for aneurysmal subarachnoid haemorrhage. Cochrane Database Syst Rev 2005;(1):CD000277.

42. Dorhout Mees SM, Rinkel GJ, Feigin VL, Algra A, van den Bergh WM, Vermeulen M, et al. Calcium antagonists for aneurysmal subarachnoid haemorrhage. Cochrane Database Syst Rev 2007;18:CD000277.

43. Roos YB, Levi M, Carroll TA, Beenen LF, Vermeulen M. Nimodipine increases fibrinolytic activity in patients with aneurysmal subarachnoid hemorrhage. Stroke 2001;32:1860-2.

44. Jun P, Ko NU, English JD, Dowd CF, Halbach VV, Higashida RT, et al. Endovascular treatment of medically refractory cerebral vasospasm following aneurysmal subarachnoid hemorrhage. AJNR Am J Neuroradiol 2010;31:1911-6.

45. Shankar JJ, dos Santos MP, Deus-Silva L, Lum C. Angiographic evaluation of the effect of intra-arterial milrinone therapy in patients with vasospasm from aneurysmal subarachnoid hemorrhage. Neuroradiology 2011;53:123-8.

46. Smith WS, Dowd CF, Johnston SC, Ko NU, DeArmond SJ, Dillon WP, et al. Neurotoxicity of intra-arterial papaverine preserved with chlorobutanol used for the treatment of cerebral vasospasm after aneurysmal subarachnoid hemorrhage. Stroke 2004;35:2518-22.

47. Terry A, Zipfel G, Milner E, Cross DT $3^{\text {rd }}$, Moran CJ, Diringer MN, et al. Safety and technical efficacy of over-the-wire balloons for the treatment of subarachnoid hemorrhage-induced cerebral vasospasm. Neurosurg Focus 2006;21:E14.

48. Wartenberg KE, Schmidt JM, Claassen J, Temes RE, Frontera JA, Ostapkovich $\mathrm{N}$, et al. Impact of medical complications on outcome after subarachnoid hemorrhage. Crit Care Med 2006;34:617-23.

49. Manninen PH, Ayra B, Gelb AW, Pelz D. Association between electrocardiographic abnormalities and intracranial blood in patients following acute subarachnoid hemorrhage. J Neurosurg Anesthesiol 1995;7:12-6.

50. Szabo MD, Crosby G, Hurford WE, Strauss HW. Myocardial perfusion following acute subarachnoid hemorrhage in patients with an abnormal electrocardiogram. Anesth Analg 1993;76:253-8.

51. Hravnak M, Frangiskakis JM, Crago EA, Chang Y, Tanabe M, Gorcsan J $3^{\text {rd }}$, et al. Elevated cardiac troponin I and relationship to persistence of electrocardiographic and echocardiographic abnormalities after aneurysmal subarachnoid hemorrhage. Stroke 2009;40:3478-84.

52. Mayer SA, LiMandri G, Sherman D, Lennihan L, Fink ME, Solomon RA, et al. Electrocardiographic markers of abnormal left ventricular wall motion in acute subarachnoid hemorrhage. J Neurosurg 1995;83:889-96.
53. Deininger MH, Radicke D, Buttler J, Scheufler KM, Freiman T, Zentner JF. Tako-tsubo cardiomyopathy: Reversible heart failure with favorable outcome in patients with intracerebral hemorrhage. Case report. J Neurosurg 2006;105:465-7.

54. Jain R, Deveikis J, Thompson BG. Management of patients with stunned myocardium associated with subarachnoid hemorrhage. AJNR Am J Neuroradiol 2004;25:126-9.

55. Gruber A, Reinprecht A, Görzer H, Fridrich P, Czech T, Illievich UM, et al. Pulmonary function and radiographic abnormalities related to neurological outcome after aneurysmal subarachnoid hemorrhage. J Neurosurg 1998;88:28-37.

56. Gruber A, Reinprecht A, Illievich UM, Fitzgerald R, Dietrich W, Czech T, et al. Extracerebral organ dysfunction and neurologic outcome after aneurysmal subarachnoid hemorrhage. Crit Care Med 1999;27:505-14.

57. Kahn JM, Caldwell EC, Deem S, Newell DW, Heckbert SR, Rubenfeld GD. Acute lung injury in patients with subarachnoid hemorrhage: Incidence, risk factors, and outcome. Crit Care Med 2006;34:196-202.

58. Rosenberg NF, Koht A, Naidech AM. Anemia and transfusion after aneurysmal subarachnoid hemorrhage. J Neurosurg Anesthesiol 2013;25:66-74.

59. Oliveira-Filho J, Ezzeddine MA, Segal AZ, Buonanno FS, Chang Y, Ogilvy CS, et al. Fever in subarachnoid hemorrhage: Relationship to vasospasm and outcome. Neurology 2001;56:1299-304.

60. Douds GL, Tadzong B, Agarwal AD, Krishnamurthy S, Lehman EB, Cockroft KM. Influence of fever and hospital-acquired infection on the incidence of delayed neurological deficit and poor outcome after aneurysmal subarachnoid hemorrhage. Neurol Res Int 2012;2012:6.

61. Badjatia N, Fernandez L, Schmidt JM, Lee K, Claassen J, Connolly ES, et al. Impact of induced normothermia on outcome after subarachnoid hemorrhage: A case-control study. Neurosurgery 2010;66:696-700.

62. Harrigan MR. Cerebral salt wasting syndrome: A review. Neurosurgery 1996;38:152-60.

63. Qureshi AI, Suri MF, Sung GY, Straw RN, Yahia AM, Saad M, et al. Prognostic significance of hypernatremia and hyponatremia among patients with aneurysmal subarachnoid hemorrhage. Neurosurgery 2002;50:749-55.

64. Berendes E, Walter M, Cullen P, Prien T, Van Aken $H$, Horsthemke J, et al. Secretion of brain natriuretic peptide in patients with aneurysmal subarachnoid haemorrhage. Lancet 1997;349:245-9.

65. Sherlock M, O'Sullivan E, Agha A, Behan LA, Rawluk D, Brennan $\mathrm{P}$, et al. The incidence and pathophysiology of hyponatraemia after subarachnoid haemorrhage. Clin Endocrinol (Oxf) 2006;64:250-4.

66. Cowley AW Jr., Roman RJ. Control of blood and extracellular volume. Baillieres Clin Endocrinol Metab 1989;3:331-69.

67. Nagano A, Yamada Y, Miyake H, Domen K, Koyama T. Increased resting energy expenditure after endovascular coiling for subarachnoid hemorrhage. J Stroke Cerebrovasc Dis 2016;25:813-8.

68. Kasuya H, Kawashima A, Namiki K, Shimizu T, Takakura K. Metabolic profiles of patients with subarachnoid hemorrhage treated by early surgery. Neurosurgery 1998;42:1268-74.

69. Badjatia N, Monahan A, Carpenter A, Zimmerman J, Schmidt JM, Claassen J, et al. Inflammation, negative nitrogen balance, and outcome after aneurysmal subarachnoid hemorrhage. Neurology 2015;84:680-7.

70. Suarez JI, Zaidat OO, Suri MF, Feen ES, Lynch G, Hickman J, et al. Length of stay and mortality in neurocritically ill patients: Impact of a specialized neurocritical care team. Crit Care Med 2004;32:2311-7. 
71. Varelas PN, Conti MM, Spanaki MV, Potts E, Bradford D, Sunstrom C, et al. The impact of a neurointensivist-led team on a semiclosed neurosciences intensive care unit. Crit Care Med 2004;32:2191-8.
72. Samuels O, Webb A, Culler S, Martin K, Barrow D. Impact of a dedicated neurocritical care team in treating patients with aneurysmal subarachnoid hemorrhage. Neurocrit Care 2011;14:334-40. 